\title{
The North American Carbon Program Multi-Scale Synthesis and Terrestrial Model Intercomparison Project - Part 1: Overview and experimental design
}

D. N. Huntzinger ${ }^{1}$, C. Schwalm ${ }^{2}$, A. M. Michalak ${ }^{3}$, K. Schaefer ${ }^{4,5}$ A. W. King ${ }^{6}$, Y. Wei ${ }^{6}$, A. Jacobson ${ }^{4,7}$, S. Liu ${ }^{6}$,

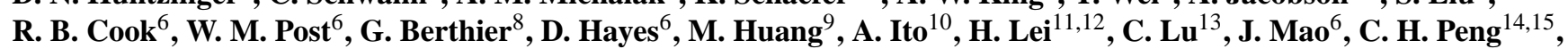

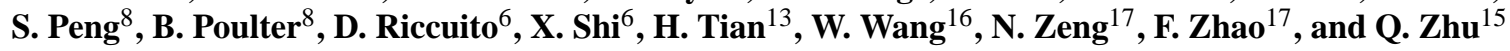

${ }^{1}$ School of Earth Sciences and Environmental Sustainability and the Department of Civil Engineering, Construction Management, and Environmental Engineering, Northern Arizona University, P.O. Box 5694, Flagstaff, Arizona, USA

${ }^{2}$ School of Earth Sciences and Environmental Sustainability, Northern Arizona University, USA

${ }^{3}$ Department of Global Ecology, Carnegie Institution for Science, Stanford, California, USA

${ }^{4}$ National Snow and Ice Data Center, Boulder, Colorado, USA

${ }^{5}$ Cooperative Institute for Research in Environmental Sciences, University of Colorado, Boulder, Colorado, USA

${ }^{6}$ Environmental Sciences Division, Oak Ridge National Laboratory, Oak Ridge, Tennessee, USA

${ }^{7}$ NOAA Earth System Research Lab Global Monitoring Division, Boulder, Colorado, USA

${ }^{8}$ Laboratoire des Sciences du Climat et de l'Environnement, LSCE, Gif sur Yvette, France

${ }^{9}$ Fundamental \& Computational Sciences, Pacific Northwest National Laboratory, Richland, Washington, USA

${ }^{10}$ National Institute for Environmental Studies, Tsukuba, Japan

${ }^{11}$ Atmospheric Sciences and Global Change Division, Pacific Northwest National Laboratory, Richland, Washington, USA

${ }^{12}$ State Key Laboratory of Hydroscience and Engineering, Department of Hydraulic Engineering, Tsinghua University, Beijing, China

${ }^{13}$ International Center for Climate and Global Change Research and School of Forestry and Wildlife Sciences, Auburn University, Auburn, Alabama, USA

${ }^{14}$ Department of Biology Sciences, Institute of Environment Sciences, University of Quebec at Montreal, C.P. 8888, Succ. Centre-Ville, Montreal H3C 3P8, Canada

${ }^{15}$ Laboratory for Ecological Forecasting and Global Change, College of Forestry, Northwest A\&F University, Yangling, Shaanxi 712100, China

${ }^{16}$ Ames Research Center, National Aeronautics and Space Administration, Moffett Field, California, USA

${ }^{17}$ Department of Atmospheric and Oceanic Science, University of Maryland, College Park, Maryland, USA

Correspondence to: D. N. Huntzinger (deborah.huntzinger@nau.edu)

Received: 24 May 2013 - Published in Geosci. Model Dev. Discuss.: 23 July 2013

Revised: 30 October 2013 - Accepted: 6 November 2013 - Published: 17 December 2013

\begin{abstract}
Terrestrial biosphere models (TBMs) have become an integral tool for extrapolating local observations and understanding of land-atmosphere carbon exchange to larger regions. The North American Carbon Program (NACP) Multi-scale synthesis and Terrestrial Model Intercomparison Project (MsTMIP) is a formal model intercomparison and evaluation effort focused on improving the diagnosis and
\end{abstract}

attribution of carbon exchange at regional and global scales. MsTMIP builds upon current and past synthesis activities, and has a unique framework designed to isolate, interpret, and inform understanding of how model structural differences impact estimates of carbon uptake and release. Here we provide an overview of the MsTMIP effort and describe how the MsTMIP experimental design enables the assessment and 
quantification of TBM structural uncertainty. Model structure refers to the types of processes considered (e.g., nutrient cycling, disturbance, lateral transport of carbon), and how these processes are represented (e.g., photosynthetic formulation, temperature sensitivity, respiration) in the models. By prescribing a common experimental protocol with standard spin-up procedures and driver data sets, we isolate any biases and variability in TBM estimates of regional and global carbon budgets resulting from differences in the models themselves (i.e., model structure) and model-specific parameter values. An initial intercomparison of model structural differences is represented using hierarchical cluster diagrams (a.k.a. dendrograms), which highlight similarities and differences in how models account for carbon cycle, vegetation, energy, and nitrogen cycle dynamics. We show that, despite the standardized protocol used to derive initial conditions, models show a high degree of variation for GPP, total living biomass, and total soil carbon, underscoring the influence of differences in model structure and parameterization on model estimates.

\section{Introduction}

Projections of future climate conditions are based, in part, on the ability to simulate the key drivers and underlying processes that control how atmospheric carbon (primarily $\mathrm{CO}_{2}$ and $\mathrm{CH}_{4}$ ) is exchanged with the terrestrial biosphere. Process-based models (a.k.a. Terrestrial Biospheric Models, TBMs) can be used to attribute carbon sources and sinks to explicit ecosystem processes, and are based on current mechanistic understanding of how carbon is exchanged with the atmosphere, and allocated or partitioned within ecosystems. Several factors influence the terrestrial carbon uptake and release predicted by models, including a model's sensitivity to climate, atmospheric composition, and nutrient and water availability. In addition, estimates from TBMs can depend strongly on environmental driver data (Poulter et al., 2011), initial conditions, and parameterizations, as well as which processes controlling carbon exchange are considered and how these processes are formulated (e.g., the functional form used to represent a particular mechanism or process) and scaled within the model. For example, whether (and how) models incorporate land-use and land cover change and other disturbances (e.g., fire) can have a significant impact on a model's prediction of net land-atmosphere carbon exchange (Liu et al., 2011). As a result, existing estimates of landatmosphere carbon exchange from TBMs vary widely (e.g., Huntzinger et al., 2012), and coupled-carbon-climate models disagree on the strength of the net land sink (when and where $\mathrm{CO}_{2}$ uptake through photosynthesis exceeds carbon losses to the atmosphere), and whether the land surface will continue to be a net sink of atmospheric $\mathrm{CO}_{2}$ under changing climatic and environmental conditions (e.g., Friedlingstein et al., 2006).
Uncertainties in, or variations among, TBM estimates are driven by a complex combination of assumptions, scientific hypotheses, and model choices (Beer et al., 2010). Ideally, TBM performance would be assessed by comparing model estimates to available observations. However, there are no direct observations of land-atmosphere carbon flux at the spatial resolutions (e.g., $0.5^{\circ}$ by $0.5^{\circ}$ ) and scales (e.g., global) needed to evaluate different model approaches, and thus guide model development and predictions of carbon exchange under future climatic conditions (Melillo et al., 1995; Heimann et al., 1998; McGuire et al., 2010). Thus, it becomes necessary to investigate, at a minimum, how inter-model differences influence variability and therefore uncertainty in results. Multi-model intercomparison projects (MIPs) help to characterize or synthesize current understanding of land-atmosphere carbon exchange, and inform the uncertainty or confidence surrounding projections of future exchange and feedbacks with the climate system.

Past MIPs have shown both the promise of using TBMs to better understand the complex carbon-climate system, as well as the challenges in evaluating model results (e.g., Melillo et al., 1995; Cramer and Field, 1999; Randerson et al., 2009; Schwalm et al., 2010; Huntzinger et al., 2012). In 2008, the North American Carbon Program (NACP) began several interim synthesis activities to evaluate and intercompare TBMs and observations at site (e.g., Schwalm et al., 2010; Schaefer et al., 2012) and regional scales (e.g., Hayes et al., 2012; Huntzinger et al., 2012).

The site synthesis focused on the comparison of observed terrestrial $\mathrm{CO}_{2}$ flux from 44 eddy covariance (EC) sites to site-level simulations from $21 \mathrm{TBMs}$, and provided a framework for evaluating model skill in terms of model structure, biome-type, and $\mathrm{CO}_{2}$ uptake in terms of seasonality and drought (Schwalm et al., 2010; Schaefer et al., 2012). However, the lack of sensitivity simulations, along with the short timescale of model runs (mean site record length $<5 \mathrm{yr}$ ) and the non-representative sample of eddy covariance sites used in the study (e.g., climate regime, ecosystem type), complicated diagnosis and attribution of overall model performance.

The NACP Regional and Continental Interim Synthesis (RCIS) activities, in contrast to the site synthesis, collected existing or "off-the-shelf" simulation results from 19 TBMs (Huntzinger et al., 2012). The decision to use existing results instead of prescribing new simulations was based largely on the need to have a "first look" synthesis of existing, mostly independent TBM results. Thus, the NACP RCIS provided a comprehensive assessment of the range of estimates of landatmosphere carbon exchange, and by extension the uncertainty associated with such estimates, including uncertainties resulting not only from model formulation and assumptions, but also from the choice of environmental driver data and spin up procedure. However, the lack of a detailed simulation protocol and consistent forcing data precluded the attribution 


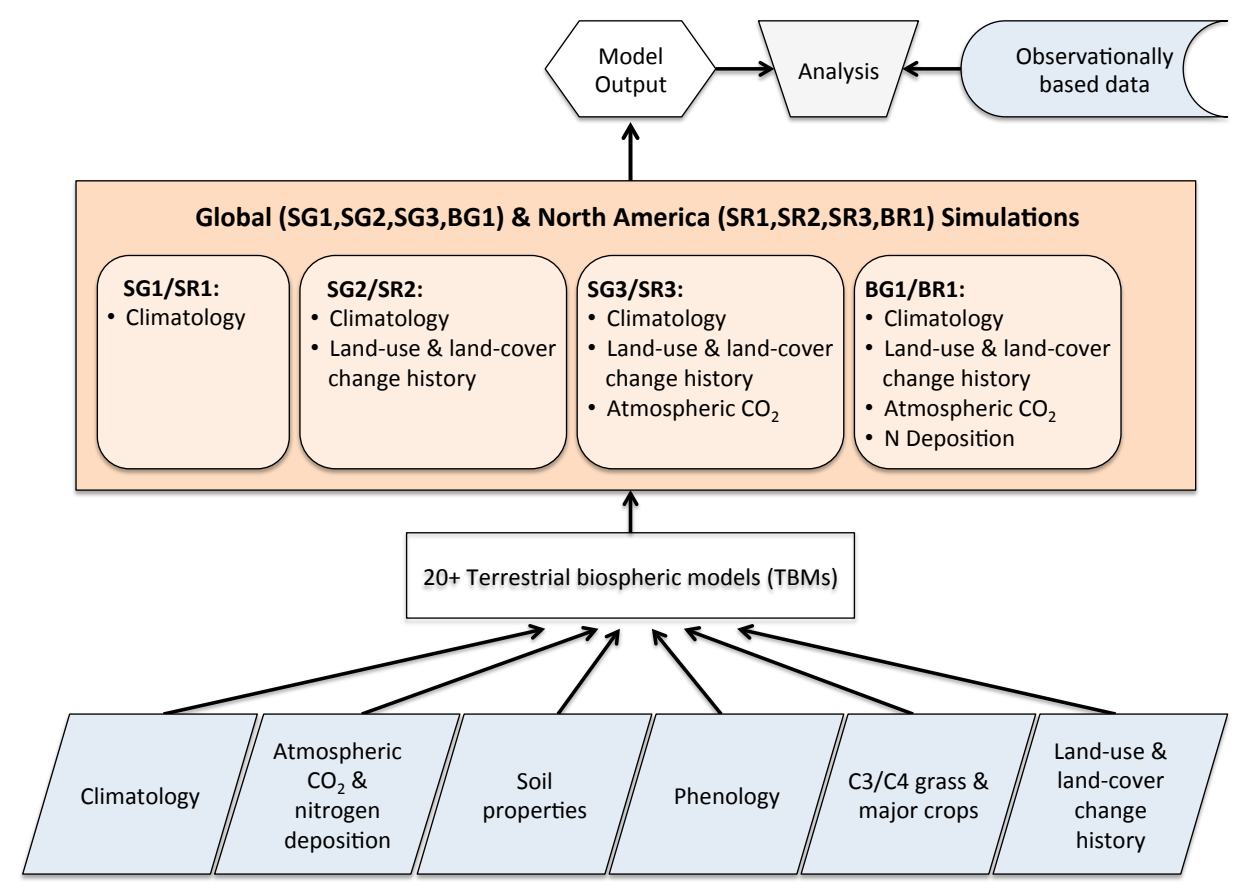

Fig. 1. Schematic of the Multi-Scale Synthesis and Terrestrial Model Intercomparison Project (MsTMIP) framework. Global simulations (SG1,SG2, SG3,BG1) are run at $0.5^{\circ}$ by $0.5^{\circ}$ resolution; North American simulations (SR1, SR2, SR3, BR1) are run at $0.25^{\circ}$ by $0.25^{\circ}$ resolution).

of observed across-model variability to differences in modeling approaches.

While the NACP RCIS and Site syntheses efforts provided a unique forum for summarizing the status of terrestrial carbon modeling, they also reinforced the need for a consistent and unified model evaluation framework in order to isolate, interpret, understand, and better address differences - primarily structural or process representations - among stateof-the-art TBMs simulating land-atmosphere exchange over continental to global extents.

This manuscript provides an overview of, and describes the experimental protocol for, the Multi-Scale Synthesis and Terrestrial Model Intercomparison Project (MsTMIP). The MsTMIP activity was created to build off of and complement recent and ongoing synthesis efforts such as the NACP RCIS and site interim synthesis activities described above, as well as the Trends in Net Land-Atmosphere Carbon Exchange (TRENDY $^{1}$ ), the regionally focused Large Scale Biosphere Atmosphere-Data Model Intercomparison Project (LBA$\mathrm{MIP}^{2}$ ), and the International Land-Atmosphere Benchmarking Project (ILAMB ${ }^{3}$; a framework confronting coupled carbon-climate models with data). The goal of MsTMIP

\footnotetext{
${ }^{1}$ http://dgvm.ceh.ac.uk/node/21.

${ }^{2} \mathrm{http}$ ://www.climatemodeling.org/lba-mip/.

${ }^{3}$ http://www.ilamb.org/.
}

is to quantify, within a unified intercomparison framework (Fig. 1), the contribution of model structural differences to across-model variability in estimates of landatmosphere carbon exchange, thus providing the critical synthesis, benchmarking, evaluation, and feedback needed to improve the current state of the art in carbon cycle modeling. The MsTMIP experimental protocol specifies standard model inputs, simulations and simulation setup procedures, as well as required model output and format to ensure a valid and fair comparison of model results against one another and against available observations. In this paper, we outline some of the key components of the MsTMIP experimental design, focusing on the participating models, key simulations, and spin-up criteria, and show how the initial steady-state results demonstrate the importance of the choices made in the experimental design.

\section{MsTMIP experimental design}

\subsection{Overview}

The MsTMIP experimental design includes simulations run at two spatial resolutions $\left(0.5^{\circ}\right.$ and $\left.0.25^{\circ}\right)$ and for two spatial domains (globally and regionally over North America) in order to assess model performance at scales relevant to carbon management and climate change predictions. The 
Table 1. Prescribed environmental driver data sets for MsTMIP simulations.

\begin{tabular}{|c|c|c|}
\hline \multirow{2}{*}{ Data type } & \multicolumn{2}{|c|}{ Temporal resolution } \\
\hline & Transient simulations ${ }^{2}$ & Spin-up and reference simulations ${ }^{3}$ \\
\hline Climate & $\begin{array}{l}\text { 6-hourly (global) } \\
\text { 3-hourly (North America) }\end{array}$ & Randomized $100 \mathrm{yr}$ data series \\
\hline $\mathrm{CO}_{2}$ concentration & Monthly & Constant 1801 values \\
\hline Nitrogen deposition & Annual & Constant 1860 values \\
\hline $\begin{array}{l}\text { Land-cover and land- } \\
\text { cover change }\end{array}$ & Annual & $\begin{array}{l}\text { Present-day mapped backwards in } \\
\text { time to } 1801 \text { using land-use, land-use } \\
\text { change. }\end{array}$ \\
\hline Phenology 1 & Monthly & Constant 1801 phenology \\
\hline $\mathrm{C} 3 / \mathrm{C} 4$ grass & Constant & Constant \\
\hline Major crops & Constant & Constant \\
\hline Soil & Constant & Constant \\
\hline Land-water mask & Constant & Constant \\
\hline
\end{tabular}

factors that influence the spatial and temporal evolution of carbon sources and sinks vary across the globe. Thus, global simulations are needed for comparing TBM results with atmospheric $\mathrm{CO}_{2}$ constraints, while North American (i.e., continental-scale) simulations provide the necessary linkage with more well-characterized land-based observational data sets. In addition, the global and North American simulations are linked to two distinct sets of standardized environmental driver data (Wei et al., 2013) in order to test the influence of both spatial resolution and changing driver data on model estimates.

Building off of lessons learned from the NACP interim synthesis activities, one of the primary goals of the MsTMIP activity is to quantify and assess the impact of TBM structural variability, and therefore uncertainty, by examining how inter-model differences influence variability among model results. Structural uncertainty results from differences across models in their representation (or lack of representation) of biogeochemical and biophysical processes. Although structural uncertainty can be quantified, in part, for a given model through a series of sensitivity simulations, it is best quantified through a MIP. To do so, however, a large ensemble of models is needed to span the range of biogeochemical and biophysical process representations, and the simulation protocol must isolate structure, at least to the extent possible, by holding constant as many aspects of simulating the terrestrial carbon cycle as feasible except for the models themselves. Using a MIP in this way cannot truly separate parametric and structural uncertainty, as different model structures will have different parameters, and models with the same process representations might use different parameter values. Nevertheless, if properly designed, observed inter-model differences can be representative of structural difference in model representation, and thus complement parametric uncertainty analyses applied to a single model.

The ability to identify particular structural contributions to inter-model variance can inform areas for model refinement and improvement, particularly if the model differences are evaluated against observation-based benchmarks of model performance (e.g., Luo et al., 2012). As such, in addition to prescribing simulations over two spatial scales and domains, the MsTMIP experimental design includes four key components to help attribute variability in model results to intermodel differences.

First, to ensure consistent and comparable model results, the MsTMIP simulations are performed using a consistent set of environmental driver data, including standard climate and atmospheric drivers, remotely sensed phenology, biome classification, and land-use history (Table 1). The rationale for the choices and the preparation of these environmental driver data products are described in detail in Wei et al. (2013).

Second, MsTMIP includes over 20 different global-scale TBMs (Table 2), representing the range of model types and complexity (e.g., dynamic versus static vegetation, prognostic versus diagnostic phenology, various treatments of disturbance events) used by the scientific community. A broad set of models is needed to gain greater insight into communitywide strengths and weaknesses in TBM model estimates, thus providing insights into the science beyond individual, potentially idiosyncratic, model properties. 
Table 2. Terrestrial biospheric models participating in the MsTMIP activity.

\begin{tabular}{|c|c|c|c|}
\hline Model name & Affiliation (team contact) & Model name & Affiliation (team contact) \\
\hline Biome-BGC & $\begin{array}{l}\text { NASA Ames } \\
\text { (Weile Wang) }\end{array}$ & JULES-JPL & $\begin{array}{l}\text { NASA Jet Propulsion Lab } \\
\text { (Joshua Fisher) }\end{array}$ \\
\hline CABLE-JPL & $\begin{array}{l}\text { NASA Jet Propulsion Lab } \\
\text { (Joshua Fisher) }\end{array}$ & LPJ-wsl & $\begin{array}{l}\text { Laboratoire des Sciences du Climat et } \\
\text { l'Environnement (LSCE), France (Ben } \\
\text { Poulter) }\end{array}$ \\
\hline CABLE & $\begin{array}{l}\text { University of Oklahoma } \\
\text { (Francesc Montane) }\end{array}$ & MC1 & $\begin{array}{l}\text { Oregon State University } \\
\text { (Dominique Bachelet) }\end{array}$ \\
\hline CLASS-CTEM-N+ & $\begin{array}{l}\text { McMaster University } \\
\text { (Altaf Arain) }\end{array}$ & ORCHIDEE-JPL & $\begin{array}{l}\text { NASA Jet Propulsion Lab } \\
\text { (Joshua Fisher) }\end{array}$ \\
\hline CLM & $\begin{array}{l}\text { Oak Ridge National Lab } \\
\text { (Dan Hayes) }\end{array}$ & ORCHIDEE-LSCE & $\begin{array}{l}\text { Laboratoire des Sciences du Climat } \\
\text { et de l'Environnement (LSCE), France } \\
\text { (Gwenaëlle Berthier) }\end{array}$ \\
\hline CLM4-VIC & $\begin{array}{l}\text { Pacific Northwest National Lab (Maoyi } \\
\text { Huang) }\end{array}$ & SiB3-JPL & $\begin{array}{l}\text { NASA Jet Propulsion Laboratory } \\
\text { (Joshua Fisher) }\end{array}$ \\
\hline DLEM & $\begin{array}{l}\text { Auburn University } \\
\text { (Hanqin Tian) }\end{array}$ & SiBCASA & $\begin{array}{l}\text { National Snow and Ice Data Center } \\
\text { (Kevin Schaefer) }\end{array}$ \\
\hline ECOSYS & $\begin{array}{l}\text { University of Alberta } \\
\text { (Robert Grant) }\end{array}$ & TEM6 & $\begin{array}{l}\text { Oak Ridge National Laboratory } \\
\text { (Dan Hayes) }\end{array}$ \\
\hline GTEC & $\begin{array}{l}\text { Oak Ridge National Lab } \\
\text { (Dan Riccuito) }\end{array}$ & TRIPLEX-GHG & $\begin{array}{l}\text { University of Quebec at Montreal } \\
\text { (Chanqhui Peng) }\end{array}$ \\
\hline HYLAND-JPL & $\begin{array}{l}\text { NASA Jet Propulsion Laboratory } \\
\text { (Joshua Fisher) }\end{array}$ & VEGAS & $\begin{array}{l}\text { University of Maryland } \\
\text { (Ning Zeng) }\end{array}$ \\
\hline ISAM & $\begin{array}{l}\text { University of Illinois Urbana Cham- } \\
\text { paign (Atul Jain) }\end{array}$ & VISIT & $\begin{array}{l}\text { National Institute for Environ. Studies, } \\
\text { Japan } \\
\text { (Akihiko Ito) }\end{array}$ \\
\hline
\end{tabular}

Table 3. Series of MsTMIP simulations.

\begin{tabular}{|c|c|c|c|c|c|c|}
\hline Domain & Name & Time period & Climate forcing & Land-use history & Atmospheric $\mathrm{CO}_{2}$ & Nitrogen deposition \\
\hline \multirow{4}{*}{$\begin{array}{l}\text { Global } \\
\left(0.5^{\circ} \text { by } 0.5^{\circ}\right)\end{array}$} & RG1 & \multirow{4}{*}{ 1901-2010 } & Constant & \multirow{3}{*}{ Constant } & \multirow{3}{*}{ Constant } & \multirow{3}{*}{ Constant } \\
\hline & SG1 & & \multirow{3}{*}{$\mathrm{CRU}+\mathrm{NCEP}^{1}$} & & & \\
\hline & $\mathrm{SG} 2$ & & & & & \\
\hline & $\begin{array}{l}\text { SG3 } \\
\text { BG1 }\end{array}$ & & & Time-varying & Time-varying & Time-varying \\
\hline \multirow{4}{*}{$\begin{array}{l}\text { North America } \\
\left(0.25^{\circ} \text { by } 0.25^{\circ}\right)\end{array}$} & RR1 & \multirow{4}{*}{ 1901-2010 } & Constant & \multirow{3}{*}{ Constant } & \multirow{3}{*}{ Constant } & \multirow{3}{*}{ Constant } \\
\hline & SR1 & & \multirow{3}{*}{$\mathrm{NARR}^{2}$} & & & \\
\hline & $\begin{array}{l}\text { SR2 } \\
\text { SR3 }\end{array}$ & & & & & \\
\hline & $\begin{array}{l}\text { SR3 } \\
\text { BR1 }\end{array}$ & & & Time-varying & Time-varying & Time-varying \\
\hline
\end{tabular}

${ }^{1}$ Climate Research Unit (CRU) + National Centers for Environmental Prediction (NCEP) global climatology. ${ }^{2}$ North American Regional Reanalysis (NARR) climatology.

Third, land-atmosphere carbon exchange is modeled over a $110 \mathrm{yr}$ period using a series of sensitivity simulations (Table 3), which allow for a robust assessment of model sensitivity to forcing factors such as climate, atmospheric $\mathrm{CO}_{2}$, nitrogen, and land cover change. The ability to characterize the contribution of processes such as climate variability, $\mathrm{CO}_{2}$ fertilization, and historical land use and disturbance on carbon stocks and net ecosystem exchange (NEE) is fundamental to understanding model representations of the terrestrial carbon cycle.
Fourth, the MsTMIP activity includes a systematic evaluation of model performance against available observationbased products in order to identify strengths and weaknesses within models and guide model development. Although direct (gridded) comprehensive observations of carbon fluxes and stocks do not exist, site level data (e.g., eddy covariance observations), inventory data (e.g., forest carbon stocks), regional gridded observations (e.g., aboveground biomass) and model-data products (e.g., data-driven spatially distributed GPP products) can be used to evaluate TBM model 
results. Comparing model predictions with available observations and data-driven products can help identify knowledge/information gaps in both the models and the observations, and advance process-level understanding of landatmosphere carbon exchange (US CCSP, 2011). This may ultimately lead to observing systems that are better optimized for evaluating model performance, as well as encouraging models to generate output that can be more directly compared with available observations.

\subsection{Participating models}

Over 20 TBMs (Table 2) with varying complexity and formulations are participating in the MsTMIP activity. This broad suite of models maximizes the degree to which insights can be gained into the uncertainties associated with TBM estimates of land-atmosphere carbon exchange. Models vary in complexity and the way in which they simulate canopy conductance (energy and water fluxes), simulate photosynthesis and respiration (carbon fluxes), allocate carbon between soil and above- and belowground biomass (carbon pools), and model vegetation dynamics and disturbances. In order to track differences in model structure and parameterizations among models, each participating modeling team completed a detailed survey specifying how their model simulates energy and water cycling, as well as carbon and vegetation dynamics. The results from these surveys can be used to identify key structural differences among the participating models.

A hierarchical cluster analysis was performed on model structural attributes in order to provide a high-level visualization of the similarities and differences among the participating models, (Figs. 2 and 3). For a given characteristic (i.e., process/attribute), a model was assigned a binary value ( 0 or 1) indicating whether it includes that particular characteristic. Thus, for each characteristic or component of the model survey, a model was given a value of one (1) if it considers or includes that process, or a zero (0) if it does not (refer to Tables S1-S4 in the Supplement). The Hamming distance (the number of "mismatches"; Hamming, 1950) was then calculated between the coded integer values for each model pair. Cluster analysis, represented as dendrograms, sorts the models into groups by the level of similarity between models; models in the same branch in the cluster tree share similar attributes. Separate dendrograms were generated comparing the similarities/differences in models overall (Fig. 2), as well as how they compare in their treatment of energy, vegetation, carbon, and nitrogen dynamics (Fig. 3). Dendrograms provide a means to easily compare overall model similarities and differences in a way that is not possible with lengthy tables summarizing various model attributes.

For the purposes of this manuscript, the dendrograms help to illustrate the range of model types and complexities in the models participating in the MsTMIP activity. For example, the models vary widely in how they formulate the energy

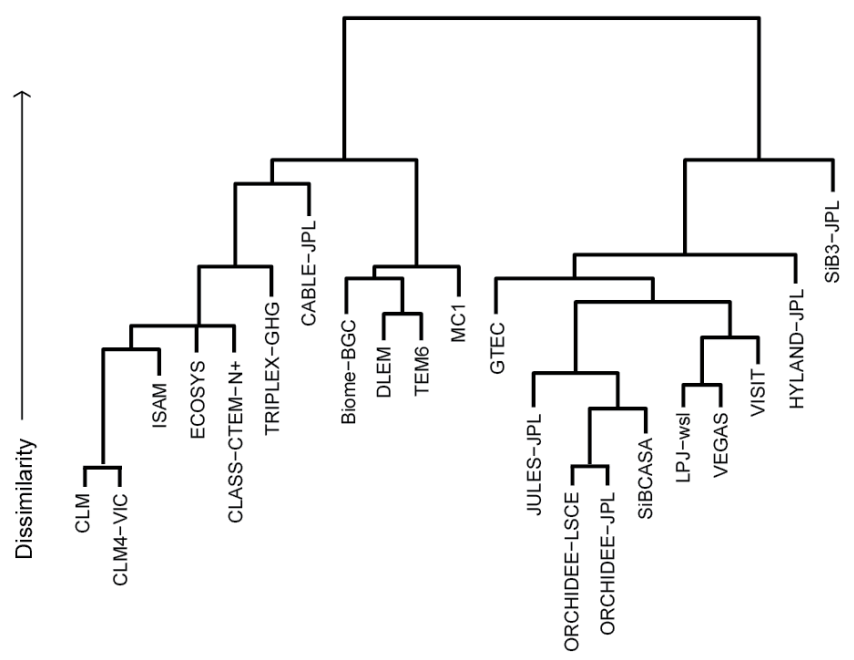

Fig. 2. Dendrogram showing overall model structural differences determined by Hamming distance for the models participating in MsTMIP. Models in the same "tree" share similar structural model characteristics. For example, models in the "tree" to the left include an explicit nitrogen cycle, while models in the "tree" to the right do not. Models are further separated or clustered by their treatment of soil carbon pools (e.g., SiB3-JPL does not include live, soil, or litter carbon pools) and their treatment of radiation and canopy heat storage (e.g., Biome-BGC, DLEM, TEM6, and MC1 do not account for canopy heat storage, nor partition radiation into latent and sensible heat). Refer to the Supplement for the binary data used to create this diagram.

cycle, including how they simulate canopy and stomatal conductance and partition net radiation between latent and sensible heat (Fig. 4a). All models account for energy fluxes, but do so in somewhat different ways. Conversely, not all models explicitly consider nitrogen cycling. Hence, two general "trees" of models appear, those that include interactive N cycling (e.g., Biome-BGC, DLEM, TEM6, CLM, CLM4VIC, TRIPLEX-GHG), and those that do not (e.g., SIBCASA, ORCHIDEE-LSCE, VEGAS, LPJ-wsl) (Fig. 4d). This diversity in model structure is needed to provide insights into our ability, as a modeling community, to simulate landatmosphere carbon dynamics.

\subsection{Simulation protocol}

Simulations are performed at two spatial scales and resolutions: (1) globally at $0.5^{\circ} \times 0.5^{\circ}$ spatial resolution; and (2) over North America at $0.25^{\circ} \times 0.25^{\circ}$ resolution. The spatial extent of the North America region is defined as $50^{\circ}$ to $170^{\circ}$ West longitude and $10^{\circ}$ to $84^{\circ}$ North latitude.

Each simulation runs from 1801 to 2010 and is divided into a common spin-up period (1801-1900) and a submission period (1901-2010). For model spin-up, a spin-up driver data package was created that includes $100 \mathrm{yr}$ of randomized weather, time-invariant preindustrial atmospheric 

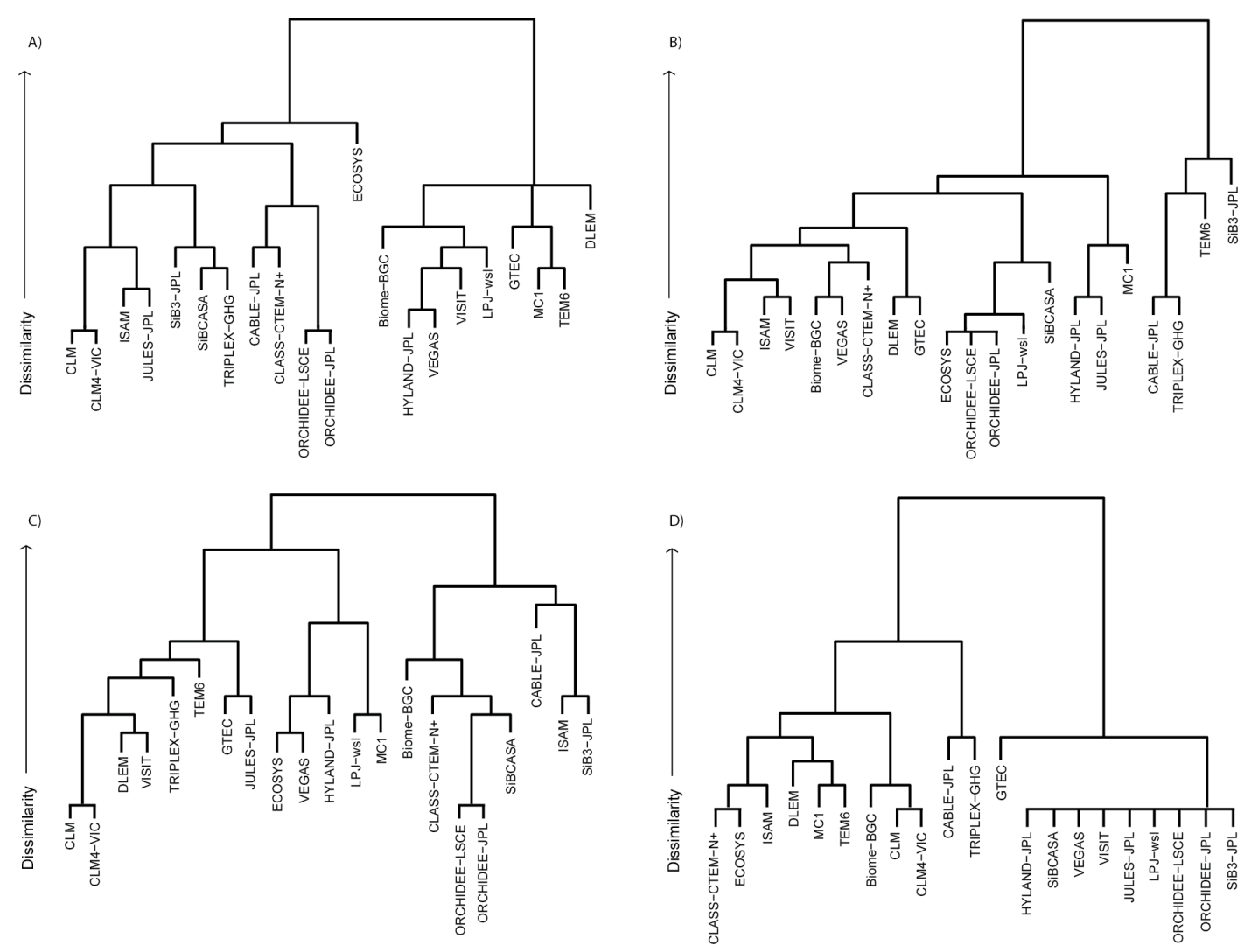

Fig. 3. Dendrogram showing general differences/similarities in how MsTMIP models formulate and parameterize (A) energy, (B) carbon, (C) vegetation, and (D) nitrogen process dynamics. Clusters are determined by Hamming distance. Models in the same "tree" share similar structural model characteristics. For example, models in the "tree" to the left (e.g., ISAM, CABLE-JPL, ORCHIDEE-JPL/LSCE) in (A) simulate ground heat flux and canopy heat storage, while models in the "tree" to the right (e.g., MC1, TEM6, VEGAS) do not. A majority of models separate live carbon into various pools (with exception of SiB-JPL), but they do so in various ways (e.g., left "tree" in (B)). Refer to the Supplement for the binary data used to create this diagram.

$\mathrm{CO}_{2}$ concentrations and nitrogen deposition rates, land-cover classification and phenology (Table 1; Wei et al., 2013). At the start of spin-up, each model's prognostic soil, canopy, and canopy air space temperatures are initialized to the average air temperature from the time period 1901 to 1930. Prognostic soil moisture variables at all soil levels are initialized to $95 \%$ of saturation, while carbon and nitrogen pools are initialized as needed for each model.

To minimize differences in model output due to differences in initial conditions, all transient simulations start from steady-state initial conditions in 1801, but models submit output only for the submission period (1901-2010). Steadystate conditions are defined as the lack of a trend in prognostic variables during the $100 \mathrm{yr}$ spin-up period (1801-1900). The steady-state criteria for the last $100 \mathrm{yr}$ of spin-up for prognostic soil temperature, soil moisture, and carbon flux are shown below and in Fig. 4a. Carbon flux depends on biomass, so the steady-state criterion for carbon flux implicitly requires that simulated carbon pools also be in equilibrium. The steady-state criteria are defined as follows:
1. For the carbon cycle, the $100 \mathrm{yr}$ mean interannual change (trend) in total ecosystem carbon stocks for consecutive years must be below $1 \mathrm{~g} \mathrm{~m}^{-2} \mathrm{yr}^{-1}$ for $95 \%$ of grid cells.

$$
\left|\Delta C_{\mathrm{eco}}\right| \leq 1 \mathrm{~g} \mathrm{~m}^{-2} \mathrm{yr}^{-2}
$$

2. For soil temperature and soil moisture, the $100 \mathrm{yr}$ trend in soil moisture and temperature should not be significantly different from zero $(\alpha=0.05)$ for at least $95 \%$ of grid cells.

Reference simulations (i.e., extended spin-up runs, RG1, RR1) are used to track model drift; and given that initial steady-state conditions can, and likely will, vary with model structure, the MsTMIP reference simulations enable examination of how steady-state conditions vary across models. A series of sensitivity simulations (SG1, SG2, SG3, SR1, SR2, SR3) are used to systematically test the additive influence of different forcing factors (i.e, climate (SG1, SR1), land-use and land-cover change (SG2, SR2), atmospheric $\mathrm{CO}_{2}(\mathrm{SG} 3$, 


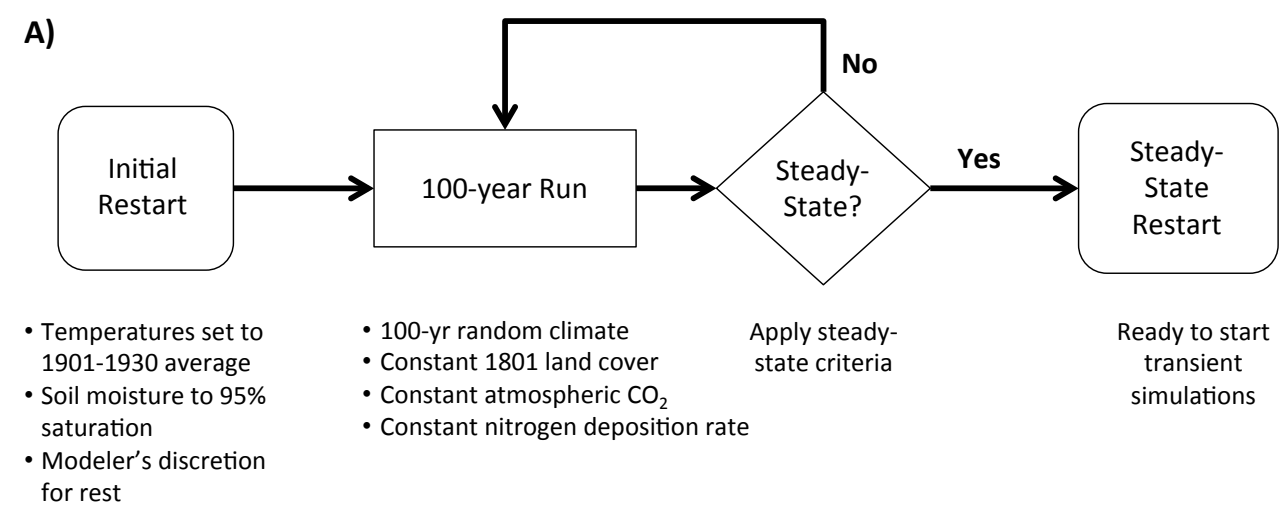

B)

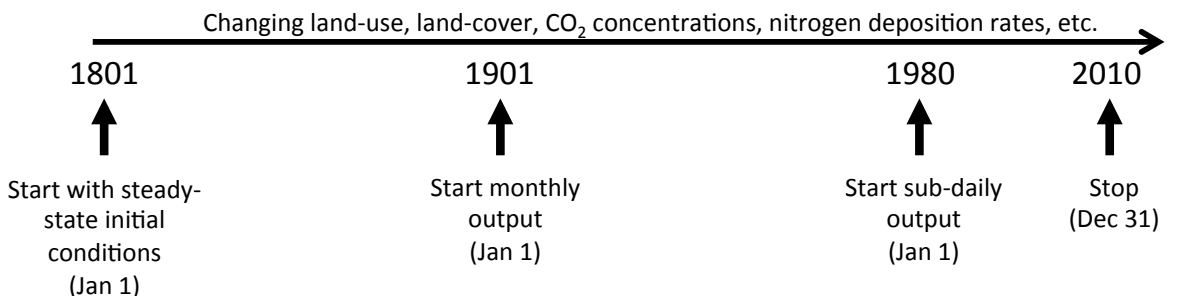

Fig. 4. Schematic of (A) the spin-up procedure to steady state; and (B) the basic timeline for each MsTMIP simulation starting from steadystate conditions reached in (A). All transient simulations (B) run from 1801 through 2010 (210 yr). The same initial conditions are used for both the global and North American simulations.

SR3), and nitrogen deposition (BG1, BR1) on model estimates of carbon stocks and fluxes. Differences between the various simulations provide insight into the effects of a particular process (e.g., nutrient limitation) or time-varying environmental drivers (e.g., atmospheric $\mathrm{CO}_{2}$ concentration) on model output. The "baseline" simulations (BG1, BR1) represent a model's best estimate of carbon exchange, with everything in the model essentially "turned-on" (Table 3). All simulations (baseline and sensitivity) follow the same spinup procedure and begin from the same (but model-specific) steady-state conditions (Fig. 2b). Parameter values are not specified as part of the MsTMIP experimental protocol, thus all models are run with their model-specific parameterizations.

\subsection{Treatment of disturbance in MsTMIP}

Disturbances transfer carbon from one pool to another (e.g., live carbon to dead carbon pools; terrestrial to atmospheric pools), and can alter forest structure (e.g., succession) and biogeochemistry (e.g., by altering soil conditions). Liu et al. (2011) highlight the importance of disturbances such as wildland fire, insect infestation, storms, and harvest on the terrestrial carbon cycle over a range of spatial and temporal scales. Understanding the role of disturbance events and their impacts is therefore critical for improving the quantification of carbon stocks and land-atmosphere carbon fluxes (Liu et al., 2011; Hayes et al., 2011); however, the current capability for robustly simulating disturbance events (and their impacts) in TBMs is limited (Liu et al., 2011). Although more work is needed in structural development and parameterization of TBMs for incorporating multiple disturbances, the limitation is probably more due to the lack of globally consistent and comprehensive data sets on historical disturbances and their future projections. Because of the lack of robust data sets on disturbance history, disturbance is not explicitly accounted for in the MsTMIP simulation protocol. Instead, models participating in MsTMIP deal with disturbances in their simulations as they normally would, and report their treatment of disturbance in the model surveys discussed in Sect. 2.2. For example, some of the models participating in MsTMIP (e.g., CLM, CLM4VIC, MC1) include disturbances such as fire prognostically (i.e., predictively), while others require a diagnostic forcing data set (e.g., TEM6, DLEM) or account for fire disturbance implicitly (e.g., through land-cover change history and remotely sensed vegetation indices) rather than explicitly.

\subsection{Output}

The output variables for each simulation are listed in Table S5 (refer to the Supplement). Variables are grouped into general categories such as carbon and energy fluxes, carbon pools, and physical variables. When applicable, variable 
names and units adhere to the ALMA standard ${ }^{4}$, and carbon cycle variable definitions follow those outlined by Chapin et al. (2006). The use of common output variable definitions is critical not only for comparing results among the TBMs, but also for comparing carbon flux estimates to those derived from other modeling approaches (e.g., atmospheric $\mathrm{CO}_{2}$ inversions). This is particularly true for derived, summarylevel carbon flux indicators, such as net ecosystem exchange (NEE) and net ecosystem carbon balance (NECB), that can be compared among different approaches across all spatial and temporal scales (Hayes and Turner, 2012). Because of structural variations, TBMs will differ in terms of which component fluxes are included in these summary-level estimates. Here, modeling teams are asked to make their "best guess" for these indicators, as allowed by their particular model and with the requirement of full transparency in the component fluxes included in each calculation. For both the global and North American simulations, monthly model output is compiled for the period 1901 to 2010. In order to compare model estimates with atmospheric $\mathrm{CO}_{2}$ concentration and FLUXNET data, carbon and energy fluxes are also collected at 3-hourly intervals for the time period of 1980 to 2010 for the reference (RG1, RR1) and baseline (BG1, BR1) simulations. For some models, however, generating 3-hourly output was not feasible. Thus, for these models, carbon and energy fluxes were collected at the finest temporal resolution possible for that model over the final $30 \mathrm{yr}$ of MsTMIP simulations.

All model submission files are CF-1.x compliant netCDF (version 3), using the standard variable names and units as listed in Table S6. The CF (Climate and Forecast) standards for writing netCDF files are described in extensive online documentation ${ }^{5}$. In past efforts (e.g., NACP RCIS and Site Synthesis), reformatting model output to a common format required significant time and effort. To avoid this problem, a library of output subroutines written in Fortran90 was created that makes it possible to write model output directly in the required submission file format. These subroutines can be inserted directly in the model code or used in a separate postprocessing program. The submission file subroutines with complete user's guide and documentation are available from the MsTMIP SVN server ${ }^{6}$.

\section{Preliminary results}

This section presents preliminary results from a subset of models participating in MsTMIP, with all results based on the RG1 simulations. Finalized MsTMIP data products will be archived at the ORNL DAAC (http://daac.ornl.gov).

\footnotetext{
${ }^{4}$ http://www.lmd.jussieu.fr/ polcher/ALMA/convention_ output_2.html.

${ }^{5}$ http://cf-pcmdi.llnl.gov/.

${ }^{6}$ https://edss-collab.ornl.gov/mstmip/svn/nc_output_routines_ fortran.
}

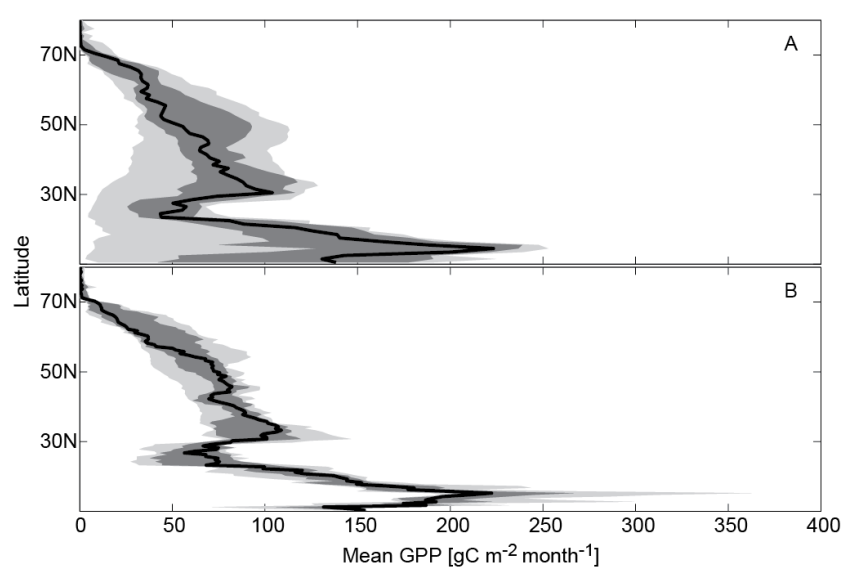

Fig. 5. North American multi-year mean (2000-2005) GPP from (A) the NACP regional and continental interim synthesis (RCIS) and (B) the MsTMIP simulations for 5 models (CLM, DLEM, LPJwsl, ORCHIDEE-LSCE, and VEGAS). On each panel, the solid line shows the median of the multi-model ensemble, the darker shaded area shows the interquartile range; and the lighter band shows the full range in estimates.

In order to evaluate the effectiveness of the MsTMIP experimental design in isolating model structural differences while controlling for other sources of variability (i.e., driver data, simulation protocol), we compare the some of the initial model results from the MsTMIP standardized protocol (Fig. 5b) to results from the NACP RCIS (Fig. 5a), an "unconstrained" protocol (varying environmental driver data, initial conditions, and spatial and temporal resolutions). Steady-state conditions for the NACP RCIS are not available, and we therefore compared the latitudinal gradients of multiyear mean gross primary productivity (GPP) from 2000 to 2005 for the five models (CLM, DLEM, LPJ, ORCHIDEELSCE, and VEGAS) common to both synthesis activities. Analogous results across all models participating in either activity (but not necessarily both) are presented in Fig. S1 (see Supplement).

As expected, there is less spread in MsTMIP results than those from the RCIS. Figure 5 shows, that by removing some of the sources of variability (i.e., choice in driver data, spinup procedure), the variability in model output is reduced, thus demonstrating the importance of the choices made in the experimental design. One reason for the decrease in variability in modeled GPP between the RCIS and MsTMIP in certain regions (e.g., topics or $\sim 10^{\circ}$ to $30^{\circ} \mathrm{N}$ in North America; Fig. 5) could be related to the quality control measures taken in preparing the environmental driver data sets for the MsTMIP activity (Wei et al., 2013). For example, known positive biases in downward shortwave radiation found in the NCEP/NCAR (Kalnay et al., 1996) were removed in the fused CRU-NCEP product created for MsTMIP (Wei et al., 2013), and as shown by Kennedy et al. (2010), biases in radiation can have a strong impact on model estimates of GPP. 

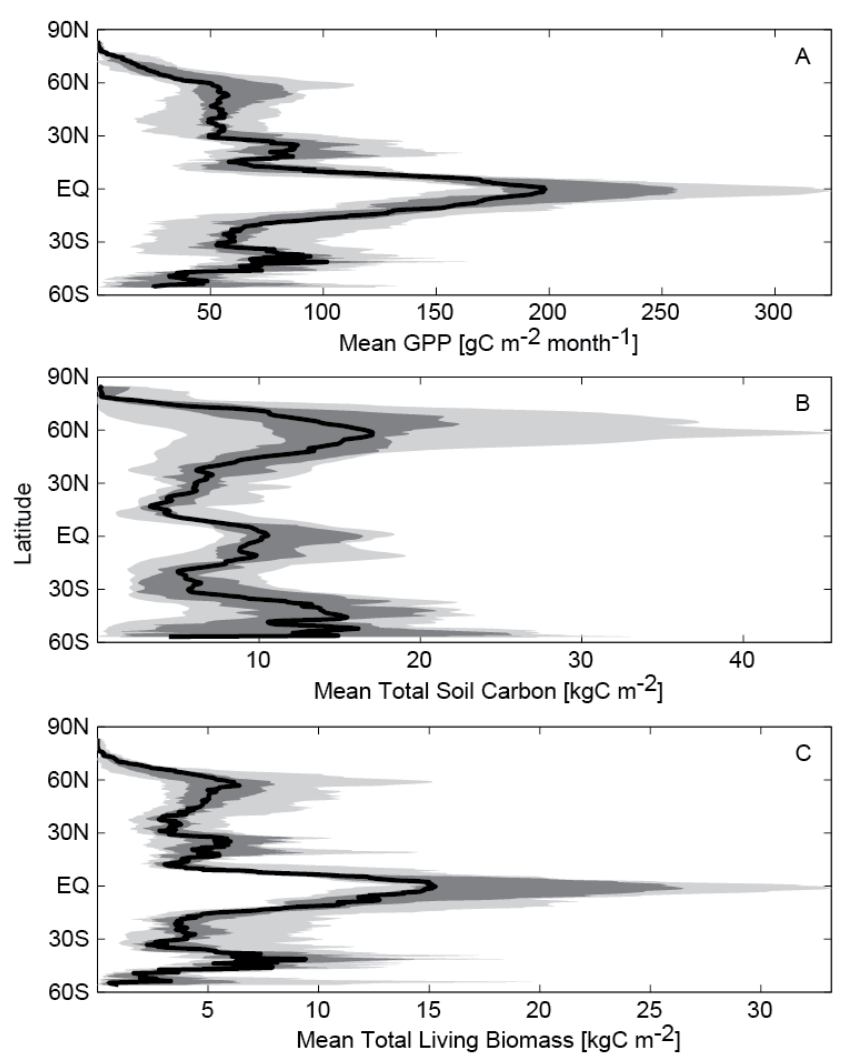

Fig. 6. Global steady-state GPP, total soil carbon, and total living biomass for 10 MsTMIP models (Biome-BGC, CLM, CLM4VIC, GTEC, LPJ-wsl, ORCHIDEE-LSCE, TRIPLEX-GHG, VEGAS, and VISIT) from the RG1 simulation. The solid black line shows the median of the multi-model ensemble, the darker grey shaded area shows the interquartile range; and the lighter grey band shows the full range in estimates.

Thus by removing known errors in environmental driver data and providing models with consistent driver data and initial conditions, the MsTMIP protocol isolates the impact of model structure on inter-model variability.

Despite the standardized protocol used to derive steadystate conditions, models show a high degree of variation for GPP, total living biomass, and total soil carbon (Fig. 6), underscoring the influence of differences in model structure on model estimates. For example, steady-state GPP estimates in the tropics vary by a factor greater than two (Fig. 6a), initial soil carbon pool sizes in the northern high latitudes ranges widely from $5-45 \mathrm{~kg} \mathrm{C} \mathrm{m}^{-2}$ (Fig. 6b), and total living biomass (Fig. 6c) varies by a factor of three in the tropics. The degree of variability is of course lower when comparing the interquartile range in order to remove any outliers (darker shaded region in Fig. 6), but the remaining inter-model differences still remain, particularly in the tropics and northern high latitudes.

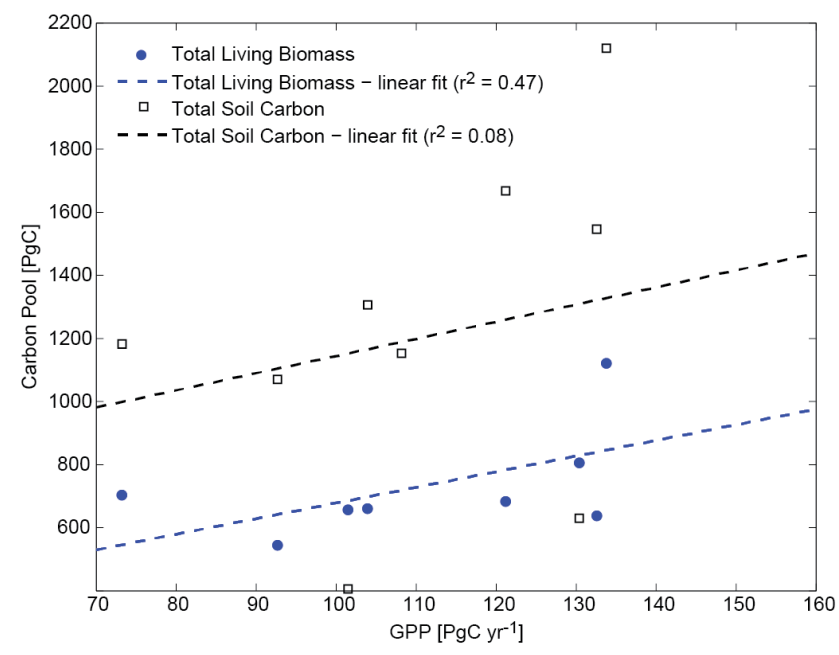

Fig. 7. Global aggregated steady-state GPP versus total soil carbon, and total living biomass for MsTMIP models from RG1 simulation.

The models also exhibit a high degree of variability in their steady-state, mean annual global totals: GPP ranges from 73 to $165 \mathrm{Pg} \mathrm{C} \mathrm{yr}^{-1}$, soil carbon from 405 to $2120 \mathrm{GtC}$, and total living biomass from 544 to $1120 \mathrm{GtC}$. For soil carbon, some of this inconsistency is related to soil depth specified in the models (varies from 1 to $6 \mathrm{~m}$ ). However, models with shallower soil profiles do not necessarily exhibit smaller pool sizes. Much of the variability in pool size (total living biomass and total soil carbon) can be linked to differences in GPP among the models (Fig. 7). Models that predict greater global annual carbon uptake generally show larger overall pool sizes. As in the NACP RCIS and Site Synthesis (Huntzinger et al., 2012; Schaefer et al., 2012), variability in model estimates appears to be strongly driven by variability in GPP, or how carbon uptake dynamics are simulated within the models. By isolating some of the sources of variability, MsTMIP's experimental design will allow for the evaluation of model results in a way that was not possible with the NACP RCIS activity.

\section{Planned analysis}

TBM model-data evaluation, or benchmarking, is one of the core components of the MsTMIP activity. Benchmarking can be defined as the organized evaluation of system performance against defined references or observations (i.e., benchmarks) (Luo et al., 2012) with the goal of diagnosing system strengths and deficiencies in order to guide model improvements. Given the complexity of models and the shortage of observational data products at the spatial and temporal resolution of model estimates, it is not possible to independently evaluate each of the modeled processes (Luo et al., 2012). There is often an inconsistency between observations and models in terms of the variables being 
measured/simulated, as well as the temporal and/or spatial resolution of the models compared to those of observations. Thus, the alternative is to use some combination of modelmodel comparisons, comparisons of model output to related observations at relevant scales; and the comparisons of model output to equivalent variables/observations at somewhat mismatched scales. In recognition of these challenges, the MsTMIP benchmarking activities will emphasize a combination of benchmarking approaches, including site eddy-covariance data (e.g., NEE, latent heat, sensible heat), regional products (e.g., aboveground biomass; Saatchi et al., 2011) and gridded model-data products (e.g., upscaled GPP from Jung et al., 2011). The model-model and model-data comparisons will target scientific questions such as: What are the dominant controls (e.g., climate, land-use, atmospheric conditions) on model estimates of global net land-atmosphere carbon exchange? What drives the variability observed in model estimates of GPP, and how do biases in GPP influence model estimates of net ecosystem exchange?

In addition, methods to evaluate model structural differences, similar to the dendrograms presented in this manuscript, will be used to attribute differences in estimates between subsets of models to differences in model structure. For example, do model estimates of global long-term mean GPP cluster similarly to model structural attributes? Such side-by-side comparisons will inform understanding of the drivers to inter-model differences in estimates of carbon fluxes and carbon pools. By better understanding the variability that emerges due to structural differences among the models, the MsTMIP activity can help inform understanding of what modeling structural choices or assumptions lead to improved model estimates. At a minimum, understanding how structural differences drive inter-model spread can help inform our understanding of model uncertainty, particularly when a discriminating choice among candidate results (e.g., which model is "best") cannot be made due to lack of available evaluation/validation data.

\section{Conclusions and outlook}

This paper provides an overview of the experimental design of the Multi-Scale Synthesis and Terrestrial Model Intercomparison Project (MsTMIP), which is being undertaken as part of the North American Carbon Program. The goal of MsTMIP is to provide, within a unified intercomparison framework, the critical synthesis and feedback needed to improve carbon cycle modeling, and quantify the contribution of model structural differences to inter-model variability. MsTMIPs experimental design, along with the large suite $(20+)$ of participating models will provide greater insight into community-wide strengths and weaknesses. In addition, the use of a consistent environmental driver data and the combination of simulations makes it possible to isolate the influence of model structural differences on model results.
Understanding how inter-model differences influence variability or uncertainty in model results is necessary for quantifying the uncertainty associated with future projections of coupled-carbon-climate feedbacks.

\section{Supplementary material related to this article is available online at http://www.geosci-model-dev.net/6/ 2121/2013/gmd-6-2121-2013-supplement.pdf.}

Acknowledgements. Funding for this project was provided through NASA ROSES Grant \# NNX10AG01A. Data management support for preparing, documenting, and distributing model driver and output data was performed by the Modeling and Synthesis Thematic Data Center at Oak Ridge National Laboratory (http://nacp.ornl.gov), with funding through NASA ROSES Grant \# NNH10AN68I. Finalized MsTMIP data products will be archived at the ORNL DAAC (http://daac.ornl.gov). This is MsTMIP contribution \#1. Acknowledgments for specific MsTMIP participating models follow.

Biome-BGC: Biome-BGC code was provided by the Numerical Terradynamic Simulation Group at University of Montana. The computational facilities provided by NASA Earth Exchange at NASA Ames Research Center.

CLM: This research is supported in part by the US Department of Energy (DOE), Office of Science, Biological and Environmental Research. Oak Ridge National Laboratory is managed by UTBATTELLE for DOE under contract DE-AC05-00OR22725.

CLM4-VIC: This research is supported in part by the US Department of Energy (DOE), Office of Science, Biological and Environmental Research. PNNL is operated for the US DOE by Battelle Memorial Institute under Contract DE-AC06-76RLO1830.

DLEM: The Dynamic Land Ecosystem Model (DLEM) developed in the International Center for Climate and Global Change Research at Auburn University has been supported by NASA Interdisciplinary Science Program (IDS), NASA Land Cover/Land Use Change Program (LCLUC), NASA Terrestrial Ecology Program, NASA Atmospheric Composition Modeling and Analysis Program (ACMAP); NSF Dynamics of Coupled Natural-Human System Program $(\mathrm{CNH})$, Decadal and Regional Climate Prediction using Earth System Models (EaSM); DOE National Institute for Climate Change Research; USDA AFRI Program and EPA STAR Program.

LPJ-wsl: This work was conducted at LSCE, France, using a modified version of the LPJ version 3.1 model, originally made available by the Potsdam Institute for Climate Impact Research.

ORCHIDEE-LSCE: ORCHIDEE is a global land surface model developed at the IPSL institute in France. The simulations were performed with the support of the GhG Europe FP7 grant with computing facilities provided by "LSCE" or "TGCC".

TRIPLEX-GHG: TRIPLEX-GHG developed at University of Quebec at Montreal (Canada) and Northwest A\&F University (China) has been supported by the National Basic Research Program of China (2013CB956602) and the National Science and Engineering Research Council of Canada (NSERC) Discover Grant.

VISIT: VISIT was developed at the National Institute for Environmental Studies, Japan. This work was mostly conducted during a visiting stay at Oak Ridge National Laboratory.

Edited by: T. Butler 


\section{References}

Beer, C., Reichstein, M., Tomelleri, E., Ciais, P., Jung, M., Carvalhais, N., Rödenbeck, C., Arain, M. A., Baldocchi, D., Bonan, G. B., Bondeau, A., Cescatti, A., Lasslop, G., Lindroth, A., Lomas, M., Luyssaert, S., Margolis, H., Oleson, K. W., Roupsard, O., Veendendaal, E., Viovy, N., Williams, C., Woodard, F. I., and Papale, D.: Terrestrial gross cabon dioxide uptake: Global distribution and covariation with climate, Science, 329, 834-838, doi:10.1126/science1184984, 2010.

Chapin III, F. S., Woodwell, G. M., Randerson, J. T., Rastetter, E. B., Lovett, G. M., Baldocchi, D. D., Clark, D. A., Harmon, M. E., Schimel, D. S., Valentini, R., Wirth, C., Aber, J. D., Cole, J. J., Goulden, M. L., Harden, J. W., Heimann, M., Howarth, R. W., Matson, P. A., McGuire, A. D., Melillo, J. M., Mooney, H. A., Neff, J. C., Houghton, R. A., Pace, M. L., Ryan, M. G., Running, S. W., Sala, O. E., Schlesinger, W. H., and Schulze, E. D.: Reconciling carbon-cycle concepts, terminology, and methods, Ecosystems, 9, 1041-1050, doi:10.1007/s10021-005-0105-7, 2006.

Cramer, W. and Field, C. B.: Comparing global models of terrestrial net primary productivity (NPP): Introduction, Glob. Change Biol., 5, iii-iv, doi:10.1046/j.1365-2486.1999.00001.x, 1999.

Friedlingstein, P., Cox, P., Betts, R., Bopp, L., von Bloh, W., Brovkin, V., Cadule, P., Doney, S., Eby, M., Fung, I., Bala, G., John, J., Jones, C., Joos, F., Kato, T., Kawamiya, M., Knorr, W., Lindsay, K., Matthews, H. D., Raddatz, T., Rayner, P., Reick, C. P., Roeckner, E., Schnitzler, K.-G., Schnur, R., Strassmann, K., Weaver, A. J., Yoshikawa, C., and Zeng, N.: Climate-carbon cycle feedback analysis: Results from the $\mathrm{C}^{4} \mathrm{MIP}$ model intercomparison, J. Climate, 19, 3337-3353, 2006.

Hamming, R. W.: Error detecting and error correcting codes, Bell System Tech. J., 29, 147-160, 1950.

Hayes, D. J., McGuire A. D., Kicklighter D. W., Gurney K. R., Burnside T. J., and Melillo J. M.: Is the northern high latitude land-based $\mathrm{CO}_{2}$ sink weakening?, Global Biogeochem. Cy., 25, GB3018, doi:10.1029/2010gb003813, 2011.

Hayes, D. J. and Turner, D. P.: The need for "apples-to-apples" comparisons of carbon dioxide source and sink estimates, EOS, 93, 404-405, doi:10.1029/2012EO410007, 2012.

Hayes, D. J., Turner, D. P., Stinson, G., McGuire, A. D., Wei, Y., West, T. O., Heath, L. S., deJong, B., McConkey, B. G., Birdsey, R. A., Kurz, W. A., Jacobson, A. R., Huntzinger, D. N., Pan, Y., Post, W. M., and Cook, R. B.: Reconciling Estimates of the Contemporary North American Carbon Balance Among an Inventory-Based Approach, Terrestrial Biosphere Models, and Atmospheric Inversions, Global Biogeochem. Cy., 18, 12821299, doi:10.1111/j.1365-2486.2011.02627.x, 2012.

Heimann, M., Esser, G., Haxeltine, A., Kaduk, J., Kicklighter, D. W., Knorr, W., Kohlmaier, G. H., McGuire, A. D., Melillo, J., Moore III, B., Otto, R. D., Prentice, I. C., Sauf, W., Schloss, A., Sitch, S., Wittenberg, U., and Würth, G.: Evaluation of terrestrial carbon cycle models through simulations of the seasonal cycle of atmospheric $\mathrm{CO}_{2}$ : First results of a model intercomparison study, Global Biogeochem. Cy., 12, 1-24, doi:10.1029/97GB01936, 1998.

Huntzinger, D. N., Post, W. M., Wei, Y., Michalak, A. M., West, T. O., Jacobson, A. R., Baker, I. T., Chen, J. M., Davis, K. J., Hayes, D. J., Hoffman, F. M., Jain, A. K., Liu, S., McGuire, A. D., Neilson, R. P., Potter, C., Poulter, B., Price, D., Raczka, B. M., Tian, H. Q., Thornton, P., Tomelleri, E., Viovy, N., Xiao, J.,
Yuan, W., Zeng, N., Zhao, M., and Cook, R.: North American Carbon Project (NACP) Regional Interim Synthesis: Terrestrial Biospheric Model Intercomparison, Ecol. Model., 224, 144-157, 2012.

Jung, M., Reichstein, M., Margolis, H. A., Cescatti, A., Richardson, A. D., Arain, M. A., Arneth, A., Bernhofer, C., Bonal, D., Chen, J., Gianelle, D., Gobron, N., Kiely, G., Kutsch, W., Lasslop, G., Law, B. E., Lindroth, A., Merbold, L., Montagnani, L. Moors, E. J., Papale, D., Sottocornola, M., Vaccari, M., and Williams, C.: Global patterns of land-atmosphere fluxes of carbon dioxide, latent heat, and sensible heat derived from eddy covariance, satellite and meteorological observations, J. Geophys. Res., 116, G00J07, doi:10.1029/2010JG001566, 2011.

Kalnay, E., Kanamitsu, M., Kistler, R., Collins, W., Deaven, D., Gandin, L., Iredell, M., Saha, S., White, G., Woollen, J., Zhu, Y., Leetmaa, A., and Reynolds, R.: The NCEP/NCAR 40-yr reanalysis project, Bull. Am. Meteorol. Soc., 77, 437-471, 1996.

Kennedy, A., Dong, X., Xi, B., Xie, S., Zhang, Y., and Chen, J.: A comparison of MERRA and NARR reanalysis with the DOE ARM SGP continuous forcing data, AGU fall meeting 2010, San Francisco, California, USA, 13-17 December, 2010.

Liu, S., Bond-Lamberty, B., Hicke, J. A., Vargas, R., Zhao, S., Chen, J., Edburg, S. L., Hu, Y., Liu, J., McGuire, A. D., Xizo, J., Keane, R., Yuan, W., Tang, J., Luo, Y., Potter, C., and Oeding, J.: Simulating the impacts of disturbances on forest carbon cycling in North America: Processes, data, models, and challenges, J. Geophys. Res., 116, G00K08, doi:10.1029/2010JG001585, 2011.

Luo, Y. Q., Randerson, J. T., Abramowitz, G., Bacour, C., Blyth, E., Carvalhais, N., Ciais, P., Dalmonech, D., Fisher, J. B., Fisher, R., Friedlingstein, P., Hibbard, K., Hoffman, F., Huntzinger, D., Jones, C. D., Koven, C., Lawrence, D., Li, D. J., Mahecha, M., Niu, S. L., Norby, R., Piao, S. L., Qi, X., Peylin, P., Prentice, I. C., Riley, W., Reichstein, M., Schwalm, C., Wang, Y. P., Xia, J. Y., Zaehle, S., and Zhou, X. H.: A framework for benchmarking land models, Biogeosciences, 9, 3857-3874, doi:10.5194/bg-93857-2012, 2012.

McGuire, A. D., Hayes, D. J., Kicklighter, D. W., Manizza, M., Zhuang, Q., Chen, M., Follows, M. J., Gurney, K. R., McClelland, J. W., Melillo, J. M., Peterson, B. J., and Prinn, R. G.: An analysis of the carbon balance of the Arctic Basin from 1997 to 2006, Tellus, 62B, 455-474, doi:10.1111/j.16000889.2010.00497.x, 2010.

Melillo, J. M., Borchers, J., Chaney, J., Fisher, H., Fox, S., Haxeltine, A., Janetos, A., Kiclighter, D. W., Kittel, T. G. F., McGuire, A. D., McKeown, R., Neilson, R., Nemani, R., Ojima, D. S., Painter, T., Oan, Y., Parton, W. J., Pierce, L., Pitelka, L., Prentice, C., Rizzo, B., Rosenbloom, N. A., Running, S., Schimel, D. S., Sitch, S., Smith, T., and Woodward, I.: Vegetation ecosystem modeling and analysis project - Comparing biogeography and biogeochemistry models in a continental-scale study of terrestrial ecosystem responses to climate-change and $\mathrm{CO}_{2}$ doubling, Global Biogeochem. Cy., 9, 407-437, 1995.

Poulter, B., Frank, D. C., Hodson, E. L., and Zimmermann, N. E.: Impacts of land cover and climate data selection on understanding terrestrial carbon dynamics and the $\mathrm{CO}_{2}$ airborne fraction, Biogeosciences, 8, 2027-2036, doi:10.5194/bg-8-20272011, 2011.

Randerson, J. T., Hoffman, F. M., Thornton, P. E., Mahowald, N. M., Lindsay, K., Lee, Y.-H., Nevison, C. D., Doney, S. C., Bo- 
nan, G., Stockli, R., Covery, C., Running, S. W., and Fung, I. Y.: Systematic assessment of terrestrial biogeochemistry in coupled climate-carbon models, Glob. Change Biol., 15, 2462-2484, doi:10.1111/j.1365-2486.2009.01912.x, 2009.

Saatchi, S. S., Harris, N. L., Brown, S., Lefsky, M., Mitchard, E. T., Salas, W., Zutta, B. R., Buermann, W., Lewis, S. L., Hagen, S., Petrova, S., White, L., Silman, M., and Morel, A.: Benchmark map of forest carbon stocks in tropical regions across three continents, Proceedings of the National Academy of Sciences, 108(24), 9899-9904, 2011.

Schaefer, K., Schwalm, C., Williams, C., Arain, M. A., Barr, A., Chen, J., Davis, K. D., Dimitrov, D., Hilton, T. W., Hollinger, D. W., Humphreys, E., Poulter, B., et al. : A model-data comparison of gross primary productivity: results from the North American Carbon Program site synthesis, J. Geophys. Res.-Bio., 117, G3, doi:10.1029/2012JG001960, 2012.
Schwalm, C. R., Williams, C. A., Schaefer, K., Anderson, R., Arain, M. A., Baker, I., et al.: A model-data intercomparison of $\mathrm{CO}_{2}$ exchange across North America: Results from the North American Carbon Program site synthesis, J. Geophys. Res.-Bio., 115, G3, doi:10.1029/2009JG001229, 2010.

US Carbon Cycle Science Plan: A Report of the Carbon Cycle Science Steering Group and Subcommittee, A. Michalak, R. Jackson, G. Marland, C. Sabine, Co-Chairs, 2011.

Wei, Y., Liu, S., Huntzinger, D. N., Michalak, A. M., Viovy, N., Post, W. M., Schwalm, C. R., Schaefer, K., Jacobson, A. R., Lu, C., Tian, H., Ricciuto, D. M., Cook, R. B., Mao, J., and Shi, X.: The North American Carbon Program Multi-scale Synthesis and Terrestrial Model Intercomparison Project - Part 2: Environmental driver data, Geosci. Model Dev. Discuss., 6, 5375-5422, doi:10.5194/gmdd-6-5375-2013, 2013. 